\title{
Ascending Bloom's Pyramid: Fostering Student Creativity and Innovation in Academic Library Spaces
}

\section{Mark Bieraugel and Stern Neill}

\begin{abstract}
Our research examined the degree to which behaviors and learning associated with creativity and innovation were supported in five academic library spaces and three other spaces at a mid-sized university. Based on survey data from 226 students, we apply a number of statistical techniques to measure student perceptions of the types of learning and behavior associated with the selected spaces. We found that the on-campus makerspace located outside the library encouraged the most innovative behaviors and exploration of new ideas. Within the library, collaboration rooms were the best spaces for encouraging creativity. There is an opportunity for the academic library to be reconceptualized as a place to foster creativity and innovation in students. We believe that academic libraries should continue to offer a variety of spaces for students, including quiet spaces for reflection, noisy spaces for collaboration and networking, and makerspaces for experimentation.
\end{abstract}

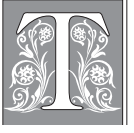

he academic library is traditionally a place for students to do research, to study, and, ultimately, to learn. However, academic libraries can also strive to provide spaces that foster creativity and innovation in support of their institution's educational goals and mission. For our research, we asked the question, "To what degree do our library spaces help foster creative and innovative thinking?" Our research question can also be a driver for considering the impact of space design within the library to encourage creativity and innovation in students. We believe that to continue to be of value for students and to align with university learning outcomes, the academic library must provide spaces that encourage creative and innovative thinking.

Our research aims to take a closer look at what types of spaces foster creativity and innovation at one institution. We examined one academic library and select campus spaces in an effort to determine which spaces foster creativity and innovation in students and to assess the degree to which academic spaces support a) learning based on existing or new knowledge and experiences and b) behaviors that are directly associated with innovation and creativity.

Mark Bieraugel is the Business Librarian in the Robert E. Kennedy Library and Stern Neill is a Professor in the Orfalea College of Business at California Polytechnic State University; e-mail: mbieraug@calpoly. edu, sneill@calpoly.edu. (C2017 Mark Bieraugel and Stern Neill, Attribution-NonCommercial (http:// creativecommons.org/licenses/by-nc/3.0/) CC BY-NC. 
One way to think about this shift from studying and learning spaces to creative spaces is to use Bloom's Taxonomy as a guide. ${ }^{1}$ Bloom's Taxonomy classifies different levels of thinking used while learning from the simple act of remembering to the most complex act of creating new or original work. Many aspects of Bloom's Taxonomy are already supported within a library including remembering information, gaining understanding of a topic, analyzing information, and evaluating information. What is not fully addressed within academic library spaces is the top of Bloom's Taxonomy pyramid: creating new knowledge. We argue that librarians should look beyond the role of storing and serving up existing knowledge and examine the academic library as a place of discovery and development.

The purpose of this paper is to determine if spaces in the library and on campus foster learning, creativity, and innovation. It also looks at the library's ability to provide spaces that support different types of learning and behavior. Next, the paper empirically investigates student perceptions of spaces within an academic library and concludes with the results and a discussion of the implications.

\section{Types of Learning and Behavior Associated with Creativity and Innovation}

For this paper, we use Margaret Boden's definition of creativity: "creativity is the ability to come up with ideas or artifacts that are new, surprising, and valuable" 2 and define innovation as the application of creativity within an organization for practical purposes. ${ }^{3}$ Organizational and entrepreneurial research proposes different types of learning and behaviors associated with creativity and innovation. In examining the role of library space in supporting innovation and creativity, this paper examines two types of learning (exploitation and exploration) and five types of behavior (observing, questioning, experimenting, networking, and reflection). Exploitation emphasizes existing knowledge and prior experience, while exploration involves search, experimentation, and the pursuit of new knowledge. ${ }^{4}$ The familiar and routine allow for the accumulation of experience and the refinement and extension of existing knowledge, while the novel and original allow for the creation of new insights and discovery and the development of new alternatives. Both are associated with innovation but represent different learning trajectories: exploitation occurs along existing paths, whereas exploration moves in entirely new directions. ${ }^{5}$ While the tendency is to exploit what is known, innovation and creativity often require exploration of the unknown; yet the known serves as a foundation to recognize what is not known and leverage it into something new and different. In this way, the individual engages in learning by relying on both existing and new knowledge and experience with each fostering creativity and innovation.

To acquire a volume and variety of information that facilitates creativity through connecting potentially disparate ideas, entrepreneurs have been shown to engage in four behaviors: observing, questioning, experimenting, and networking. ${ }^{6}$ To these four, a fifth behavior - reflecting - is added, which also represents an important component of entrepreneurial creativity. ${ }^{7}$ Behaviorally, entrepreneurs engage in actions that allow them access to a volume and variety of information. Interacting with experiences, ideas, and people exposes the individual to different and possibly ambiguous information and provides source material for novel insights. These behaviors support the creative process, allowing individuals to acquire information-including feedback-and develop creative insights and innovative opportunities. In this way, creativity is a function of individual engagement with the world and with ideas.

\section{Literature Review}

Creativity scholarship is a broad field, encompassing many different disciplines. For our purposes, we examined the literature of creativity on college campuses and in 
academic library spaces. We also examined the literature of how spaces influence creativity and how businesses, public institutions, and universities have created spaces aimed at fostering creativity and innovation.

In 2004, Steven Tepper noted that no one has "ever tried to measure the creative environment in American colleges" and that "creativity remains an undervalued policy goal for colleges and universities." ${ }^{8}$ Tepper examines structural conditions for fostering creativity on college campuses and calls for colleges to make measuring and assessing creativity a priority. That is what our study aims to do for spaces. However, we cannot lose sight of the importance of libraries as places for reflective learning and critical reflection. ${ }^{9}$ As David Carr notes, museums and libraries are "public places intended for learners, and for lives of self-invention and pursuit, and as places for reflection, critical thinking, and as a "place for possibility." 10 The value of an academic library as a physical space for studying and learning has been much studied, but the value of academic library space for fostering creative and innovative thinking has received considerably less attention. ${ }^{11}$ Some researchers have approached fostering creativity and innovation in academic libraries through play ${ }^{12}$ or through makerspaces. ${ }^{13}$ The physical environment where service is delivered performs multiple functions: as a package (establishing expectations), a facilitator (aiding performance), a socializer (enhancing interactions), and a differentiator (demarcating spaces). ${ }^{14}$ The configuration of the physical environment, which includes layout, equipment, ambient conditions, signs, and symbols, influences individual thinking and behavior in both positive and negative ways. ${ }^{15}$ Researchers of both academic and business environments suggest that there is a need for different spaces for different stages of creativity and innovation.

Lennie Scott-Weber posits that space affects a person's behavior and that the key is designing those learning spaces for the intended behavior. ${ }^{16}$ The author calls for different types of learning spaces depending on the current needs of students in what she calls the "caves and commons" approach: private "caves" when you need to work alone and quietly, public "commons" when you need to collaborate with others in an open space. Janetta Mitchell McCoy and Gary W. Evans studied the impact of interior design on the creativity of college students. ${ }^{17}$ For part of their study, students sat in two distinct spaces, a library foyer and a traditional classroom, and took creativity tests to determine the impact of the environment on their creativity. The authors found that the library space did little to foster creativity in the students. Through their findings, the authors developed a set of interior design factors that can enhance or dampen creativity. They found views out a window, particularly to nature, are perceived to enhance creativity. Markus F. Peschl and Thomas Fundneider also examined the use of library spaces and creativity; however, the authors only examined how space was used (such as for collaborative work or reading a magazine) and not how likely students would engage in creative or innovative behaviors within that space. ${ }^{18}$ Tore Kristensen and Kerstin Sailer both found that physical space design for businesses can foster creativity in employees and that creativity requires a combination of group and private spaces. ${ }^{19}$

\section{Designed and Built Creativity Spaces}

Businesses, public institutions, and academic libraries have all designed and built specific spaces to encourage creativity and innovation for the participants visiting these locations. These dedicated spaces are staffed with trained facilitators who help people work through the creative process. Businesses first developed "collaboration rooms" in the 1980s followed by "innovation labs" developed by UK-based public institutions in the early 2000s. More recently, an academic library built a space for fostering creativity in 2010. Businesses consulting firm MG Taylor was one of the first companies to design specific spaces to foster creativity and innovation in organiza- 
tions and businesses. ${ }^{20}$ They created Navigation Centers - rich, interactive workspaces that use "thought games, color, artistic supplies, toys" to facilitate innovation. ${ }^{21}$ Joyce Wycoff and Lynn Snead also reported on "collaboration rooms," specifically built spaces nested within existing businesses for the purpose of helping teams generate new ideas and increase collaboration. These special rooms are often the antithesis of bland corporate environments, with lots of toys, whiteboards on every wall, interesting lighting, and garden-like spaces. ${ }^{22}$

Udo-Ernst Haner also reported on dedicated spaces for creativity at businesses. ${ }^{23}$ Haner studied two work environments designed to foster creativity and innovation, the Interactive Creativity Landscape (ICL) and The Learning Garden, with the ICL as part of the normal workspace for individuals and the Learning Garden a dedicated space for groups only. Both spaces were designed specifically to foster each of the phases of creativity posited by Walas. Haner notes that most workplaces are designed for one use, whereas to support creativity and innovation there needs to be a variety of spaces for each of the stages of creativity and innovation. Unfortunately, no academic researcher has studied how well these collaboration rooms improved creativity and innovation within a business. ${ }^{24}$

Public institutions in the United Kingdom, including the Royal Mail and the Department of Trade and Industry, developed stand-alone "innovation labs" in the early 2000s according to Lewis and Moultrie. ${ }^{25}$ These spaces were designed with the goal of improving creativity, innovation, and collaboration within their parent organizations. The innovation labs helped teams generate new ideas, work together, and reinforce the "corporate commitment to innovation and creativity by providing a physical manifestation of dynamic capability and double-loop learning concepts." ${ }^{26}$ Following up on Lewis and Moultrie's research, Wissam Magadley and Kamal Birdi examined the effectiveness of idea generation at U.K.-based innovation labs. They found that participants using the labs generated many useful ideas during the sessions, but the ideas generated were not extremely original. ${ }^{27}$ This points to a possible weakness in stand-alone, dedicated spaces for fostering creativity, in that the space is less important than the facilitation and time separate from a typical work environment.

\section{Library Spaces for Learning, Experimenting, and Fostering Creativity}

Students who come to an academic library encounter a variety of spaces that influence their learning and behavior. In his important paper, Jeffrey Gayton states the academic library has two types of spaces: communal and social. ${ }^{28}$ Communal spaces are places where students are engaged in solitary, studious, and contemplative study surrounded by other students. Students engage in collaborative and noisy work with other students in social spaces. Gayton's idea of library spaces-different types for different student needs - supports our idea that students need distinct spaces for the types of learning and behavior associated with creativity and innovation. Similar to Gayton's ideas of library space, Scott Bennett argues that, when designing learning spaces in a library, it is crucial to consider what types of behavior the design will elicit. ${ }^{29}$ Hannah Bennett's discussion of library design, as seen through the lens of neuroscience, is intriguing and posits that library space is similar to "productive research environments" in fostering creativity and innovation. Bennett notes that Google, Twitter, Facebook, and other companies also aim to create productive research environments within corporate settings "to cultivate innovation and creative thinking be it in the lobby, cafeteria, or a quiet corner." 30

Advancing the idea of adding experimentation and creativity to library spaces, Megan Lotts examined how academic libraries can create a culture of creativity with low-cost activities by using temporary spaces where students make things. ${ }^{31}$ Recently, 
Lotts discussed a more permanent method of fostering student creativity in the library: buckets of Lego ${ }^{\circledR}$ bricks on tables, ready to be used by students to make whatever they want. ${ }^{32}$ Lotts notes that, as universities move from a teaching culture to a learning culture, there is a need to embrace social forms of learning, not just the solitary learner. Jennifer Sparrow and Susan Whitmer discuss learning space design in higher education and include "maker, hacker, innovation spaces" as one of their six campus learning spaces. ${ }^{33}$ They note that these types of spaces aim to develop "a culture of innovation across campus" and that libraries are ideal as a central location for these types of spaces as they are easily accessed by more students. A number of larger universities have built spaces to foster creativity including MIT's Media Lab, The Lab at Harvard University, and Stanford University's d.school. ${ }^{34}$ These spaces, part of a larger trend toward fostering creativity beyond the arts and design, are what Tepper calls "multidisciplinary problem-focused centers." Our research examines spaces publicly available for all undergraduates to use. One university has designed and built a separate space to foster creativity within an academic library: the Noel Studio for Academic Creativity at Eastern Kentucky University. Designed with the goal of helping students communicate better, the Noel Studio includes a large space for collaborative work, a flexible classroom for teaching and learning, and a set of private rooms for practicing and recording presentations. ${ }^{35}$ The Noel Studio has trained facilitators available to assist students with idea generation, writing, and other types of communication. Bettina Gardner, Trenia L. Napier, and Russell G. Carpenter, writing on the Noel Studio, argue that changes to academic libraries have been primarily social or spatial but not driven by university goals and changes in pedagogy. ${ }^{36}$ We agree with the authors in that academic library space design should be more directly linked with both university goals and with new directions in pedagogy, specifically to develop spaces that support the types of learning and behavior we desire in our students. The Noel Studio is an interesting model for fostering creativity within academic library space and is the best example of a holistic approach for doing so. We believe their concept could be modified to encompass more than just improving communication, but to improve creativity and innovation in general in students.

\section{Method}

\section{Data Collection}

To assess how space was used, questionnaire data were collected from students using one of eight selected locations at a large, predominantly undergraduate university on the west coast, a polytechnic university with a student population predominantly in the STEM disciplines. The core campus includes the library and two main student hubs: the first is near the residence halls and includes the Student Union, and the second zone is a greenspace, located near the library, fast food locations, and many classrooms. The single campus library serves the entire population of almost 20,000 students. The chosen locations represented a variety of uses within and outside the library. The five locations within the library were selected because each is distinctly different: an atrium filled with bushes and trees, a computer lab, collaboration rooms housing up to ten people, large open tables for groups, and a quiet study zone with individual desks. The three spaces outside the library were chosen because of their popularity with students: a Greenspace, the Student Union, and a Makerspace.

Students were chosen randomly when in the locations with no attempt to create a cross-sectional representation of the student body; however, the assumption is that students chose each space based on its ability to support the learning or behavior that the student was expecting to engage in or had used the space in the past. In total, 226 students responded with at least 25 responses collected per space. Respondents repre- 
sented all colleges (architecture $=3 \%$; agriculture $=10 \%$; business $=17 \%$; engineering $=$ $37 \%$; liberal arts $=21 \%$; and science and math $=12 \%$ ) and a range of years (first $=19 \%$; second $=28 \%$; third $=22 \%$; fourth $=25 \%$; fifth or more $=6 \%$ ) at the university.

\section{Measures}

Exploiting and exploring are both approaches to creativity and innovation. While exploitation allows for the accumulation of experience and the refinement and extension of existing knowledge, exploration allows for the creation of new insights and discovery and the development of new alternatives. Exploration likely leads to more radical forms of innovation. Generally, it is desirable to foster exploration as it generates new ideas and is a more radical form of innovation, while exploiting supports a more incremental form of creativity and innovation. Another way an academic library can help students explore or exploit ideas is to provide spaces that engender various behaviors. Based on a review of the entrepreneurial literature, we identified five relevant behaviors:

1. observing situations - both ordinary and novel-by engaging the senses and being mindful of interactions and experiences.

2. questioning assumptions by asking "what if," "why," and "why not," which serves to challenge the status quo and provides an opening for insight.

3. experimenting with ideas with a hypothesis-testing mindset-learning by doing as a way of gaining insight into the workings of things and imagined possibilities.

4. networking with different ideas and people to be exposed to a variety of perspectives and extend knowledge.

5. reflecting on problems, assumptions, and experiences by stepping back and allowing thoughts and imagination to wander and connect in new ways.

The survey also included questions about how often a student used a particular space during the academic year along with demographic questions about the student's college and academic year.

To measure behaviors and learning associated with creativity and innovation, multiple item scales were used. Using multiple items to measure a concept allows for better representation of complex phenomena and the reduction of measurement error; however, the items should be unidimensional: that is to say, they should represent a single concept and be strongly associated with each other. ${ }^{37}$ For each item, students were asked to indicate the degree to which the space supported exploitative and explorative learning and five learning behaviors using a seven-point agree-disagree scale. The use of Likert scales is common in attitudinal research, as it allows for an assessment of reliability and validity when using multiple statements to measure an unobservable concept, such as student perception. A seven-point range allows for better discrimination among responses, with an odd number of scale points allowing respondents to hold a neutral position. ${ }^{38}$ Before distributing the survey, four independent reviewers were presented with a definition for each scale and evaluated the representativeness and clarity of each item, which led to some modifications to the wording of items prior to data collection.

To assess the empirical reliability of the multiple item measures, a number of analyses were performed. Unidimensionality was assessed by examining the interrelations among each scale's items using item-to-scale correlations, exploratory factor analysis, and Cronbach's alpha. ${ }^{39}$ Item-to-scale correlations assess the strength of the relationship between each item and the overall summated score of other scale items, with values exceeding .50 being acceptable. Factor analysis examines the underlying dimensionality among a set of items in a scale with the expectation that each item will load highly on its respective factor. Each factor loading therefore indicates how strongly an item 


\begin{tabular}{|c|c|c|c|c|c|c|c|}
\hline \multicolumn{8}{|c|}{$\begin{array}{c}\text { TABLE } 1 \\
\begin{array}{c}\text { Scale Items, Factor Loadings, Internal Consistency Estimates } \\
\text { and Descriptive Statistics }\end{array}\end{array}$} \\
\hline & $(1)$ & $(2)$ & (3) & $(4)$ & $(5)$ & $(6)$ & (7) \\
\hline \multicolumn{8}{|l|}{ (1) Explore $($ Mean $=5.07, \mathrm{SD}=1.30$, Alpha $=.93)$} \\
\hline develop new knowledge and skills & .20 & .03 & .01 & .42 & .07 & .71 & .18 \\
\hline develop original ideas & .16 & .09 & .16 & .13 & .12 & .85 & .23 \\
\hline explore new approaches & .21 & .09 & .19 & .16 & .16 & .82 & .23 \\
\hline develop new insights & .15 & .11 & .22 & .17 & .22 & .81 & .27 \\
\hline \multicolumn{8}{|c|}{ (2) Exploit $($ Mean $=5.12, \mathrm{SD}=1.22$, Alpha $=.89)$} \\
\hline rely on established routines & -.01 & -.01 & -.04 & .81 & .13 & .05 & -.11 \\
\hline use what you know best & .09 & .07 & .01 & .88 & .12 & .16 & .12 \\
\hline work with proven ideas & .11 & .03 & .03 & .88 & .08 & .19 & .14 \\
\hline apply what you know & .17 & .04 & .10 & .80 & .11 & .18 & .19 \\
\hline \multicolumn{8}{|l|}{ (3) Observe $($ Mean $=5.08, \mathrm{SD}=1.51$, Alpha $=.94)$} \\
\hline observe novel situations & .13 & .22 & .78 & -.04 & .00 & .19 & .22 \\
\hline develop insights by watching & .19 & .24 & .88 & .03 & .07 & .14 & .17 \\
\hline gain an understanding through observation & .21 & .34 & .81 & .08 & .06 & .11 & .20 \\
\hline learn by observing & .22 & .28 & .87 & .05 & .06 & .12 & .16 \\
\hline \multicolumn{8}{|c|}{ (4) Question $($ Mean $=5.14, \mathrm{SD}=1.34$, Alpha $=.94)$} \\
\hline spark thoughtful questions & .18 & .12 & .25 & .07 & .26 & .29 & .78 \\
\hline develop thoughtful questions & .19 & .09 & .25 & .12 & .29 & .29 & .77 \\
\hline help prompt questions & .26 & .10 & .22 & .12 & .17 & .24 & .80 \\
\hline learn by questioning & .32 & .21 & .18 & .12 & .10 & .23 & .75 \\
\hline \multicolumn{8}{|c|}{ (5) Experiment $(\mathrm{Mean}=4.21, \mathrm{SD}=1.72, \mathrm{Alpha}=.96)$} \\
\hline engage in experimentation & .85 & .20 & .21 & .09 & .01 & .12 & .24 \\
\hline examine ideas through testing & .88 & .18 & .13 & .15 & .04 & .17 & .20 \\
\hline try new ways of doing things & .83 & .23 & .20 & .11 & .10 & .24 & .15 \\
\hline learn by experimenting & .88 & .23 & .19 & .08 & .03 & .16 & .19 \\
\hline \multicolumn{8}{|c|}{ (6) Network $($ Mean $=5.10, \mathrm{SD}=1.73$, Alpha $=.95)$} \\
\hline mix with others & .21 & .85 & .25 & .02 & -.04 & .14 & .04 \\
\hline meet new people & .25 & .85 & .19 & -.05 & -.02 & .08 & .10 \\
\hline network with individuals & .18 & .89 & .26 & .10 & .03 & .00 & .11 \\
\hline learn by interacting & .12 & .87 & .26 & .05 & .00 & .06 & .17 \\
\hline \multicolumn{8}{|l|}{ (7) Reflect $($ Mean $=5.30, \mathrm{SD}=1.51$, Alpha $=.89)$} \\
\hline meditate on ideas & .11 & .11 & -.06 & .14 & .82 & .13 & .14 \\
\hline contemplate experiences & .07 & .16 & .02 & .08 & .85 & .09 & .18 \\
\hline be alone with my thoughts & -.05 & -.19 & .06 & .09 & .86 & .08 & .08 \\
\hline learn by reflecting & .02 & -.10 & .13 & .13 & .87 & .12 & .13 \\
\hline
\end{tabular}




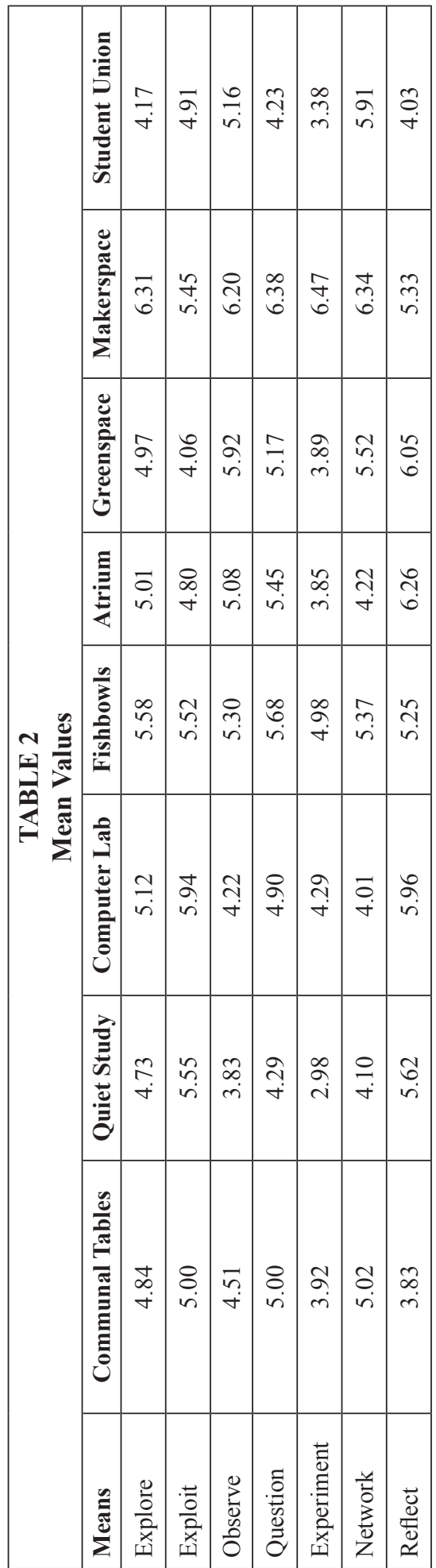

correlates with the overall scale, with higher loadings suggesting a stronger relationship. Finally, Cronbach's alpha serves as an overall measure of unidimensionality for each scale, with scores greater than .70 being acceptable.

In assessing unidimensionality among the items in this study, item-to-scale correlations exceeded .50 for each item. The items were then subjected to exploratory factor analyses to ensure that all items were loaded on their respective factor. The factor analysis results confirmed a seven-factor solution with factor loadings reported in table 1 . To aid interpretation, varimax rotation was used to provide a clearer separation among the factors, and high factor loadings are indicated in bold to better illustrate the dimensionality among the items. Also reported in table 1 are each scale's mean and standard deviation, along with Cronbach's alpha. Cronbach's alpha was calculated to gauge the reliability of the individual constructs with all scores exceeding .80, thus indicating acceptable reliability. ${ }^{40}$ No items were removed based on this analysis. Table 2 reports the mean values for each sampled space.

\section{Results}

To determine the degree to which the library supports exploiting and exploring, a paired-samples t-test was performed for the library as a whole (aggregating five library spaces) and for each sampled space within the library. A paired-samples t-test can be used to compare how individuals responded to two sets of questions. ${ }^{41}$ Table 3 compares the mean difference for each space on its ability to support exploring or exploiting, with a significant difference $(P<.05)$ suggesting that the space better supports exploiting for negative values or exploring for positive values. The library's ability to support exploitation $($ mean $=5.34)$ is significantly greater than its ability to support exploration $($ mean $=5.06)$, given a $\mathrm{t}$-value of $-2.43(P<.05)$. This is particularly the case in the Quiet Study ( $\mathrm{t}$-value $=-3.29$; $P<.01)$ and Computer Lab (t-value $=-2.98$; $P<.01)$ spaces. Outside the library, similar results are indicated for the Student Union (t-value $=-3.61 ; P<.01)$, whereas exploration 


\begin{tabular}{|l|c|c|c|}
\hline \multicolumn{4}{|c|}{ TABLE 3 } \\
Paired Samples T-test Results for Exploring and Exploiting \\
\hline Library Space & T-value & df & Significance \\
\hline Library Overall & -2.43 & 134 & .02 \\
\hline Communal Tables & -.52 & 24 & .61 \\
\hline Quiet Study & -3.29 & 24 & .00 \\
\hline Computer Lab & -2.98 & 24 & .01 \\
\hline Fishbowls & .32 & 27 & .75 \\
\hline Atrium & 1.13 & 31 & .27 \\
\hline Greenspace & 5.64 & 30 & .00 \\
\hline Makerspace & 4.45 & 26 & .00 \\
\hline Student Union & -3.61 & 31 & .00 \\
\hline Note: df=degrees of freedom & & & \\
\hline
\end{tabular}

is supported more than exploitation in the Greenspace (t-value $=5.64 ; P<.01)$ and Makerspace (t-value $=4.45 ; P<.01)$.

Next, all spaces were compared for their relative ability to support explorative and exploitative learning and five learning behaviors. Analysis of variance was used to determine whether statistically significant differences in reported means existed between groups, ${ }^{42}$ in this case among the sampled spaces for each type of learning and behavior. These results are reported in table 4 . The results indicate that the spaces differ significantly in their ability to support learning and behaviors. This is based on a determination of whether the difference in the mean values presented in table 2 are statistically significant. Based on significant F-values $(P<.05)$, the results indicate significant differences among the spaces for the behaviors and learning associated with creativity and innovation with contrasts indicating the specific spaces where the significant differences occur and the direction of the difference. Using exploration as an example, the results indicate that, within the library, the Fishbowls better support this learning relative to the Communal Tables and Quiet Study areas but no better than the Computer Lab. The Makerspace outperforms all spaces both internal and external to the library in support of exploration, whereas the Student Union underperforms relative to all spaces except for the Quiet Study. These findings are interpreted further in the Discussion section that follows.

To validate that the five learning behaviors were associated with explorative and exploitative learning, two regression analyses were performed with learning as the dependent variable and the five behaviors as independent variables. Regression analysis allows for the simultaneous examination of multiple factors on a single outcome-in this case, the combined effect of each learning behavior on learning type (exploring and exploiting), as reported in table 5. The analysis is performed for each learning type, with the beta coefficients providing an indication of the relative influence of each behavior on the respective learning type. The beta coefficients can range from +1 to -1 , with values closer to +1 or -1 having a stronger relative influence on the dependent variable. Table 5 also reports each model's significance (F-Test) along with the percentage of variance in learning type explained by the combination of learning behaviors (adjusted $\mathrm{R}^{2}$ ). A significant model indicates the presence of significant beta coefficients, while a higher $\mathrm{R}^{2}$ suggests better prediction of the dependent variable. The results, as reported in table 5, indicate that questioning, experimenting, and reflecting each contribute unique aspects to both exploring and exploiting. With an adjusted $\mathrm{R}^{2}$ 


\begin{tabular}{|l|l|l|}
\hline \multicolumn{2}{|c|}{ Analysis of Variance Results } \\
\hline Dependent Variable & F-value & Significant Contrastsa,b \\
\hline Explore & $8.15^{\text {a }}$ & $\begin{array}{l}1<4,1<7,1>8,2<4,2<7,3<7,3>8,4>6,4<7,4>8, \\
5<7,5>8,6<7,6>8,7>8\end{array}$ \\
\hline Exploit & $7.96^{\text {a }}$ & $\begin{array}{l}1<3,1>6,2>5,2>6,2>8,3>5,3>6,3>8,4>5,4>6, \\
4>8,5>6,5<7,6<7,6<8\end{array}$ \\
\hline Observe & $9.95^{\text {a }}$ & $\begin{array}{l}1<4,1<6,1<7,2<4,2<5,2<6,2<7,2<8,3<4,3<5, \\
3<6,3<7,3<8,4<7,5<6,5<7,6>8,7>8\end{array}$ \\
\hline Question & $10.35^{\text {a }}$ & $\begin{array}{l}1>2,1<4,1<7,1>8,2<4,2<5,2<6,2<7,3<4,3<7, \\
3>8,4<7,4>8,5<7,5>8,6<7,6>8,7>8\end{array}$ \\
\hline Experiment & $16.60^{\text {a }}$ & $\begin{array}{l}1>2,1<4,1>7,2<3,2<4,2<5,2<6,2<7,3<7,3>8, \\
4>5,4>6,4<7,4>8,5<7,6<7,7>8\end{array}$ \\
\hline Network & $9.05^{\text {a }}$ & $\begin{array}{l}1>2,1>3,1>5,1<7,1>8,2<4,2<6,2<7,2<8,3<4, \\
3<6,3<7,3<8,4>5,4<7,5<6,5<7,5<8,6<7\end{array}$ \\
\hline Reflect & $14.65^{\text {a }}$ & $\begin{array}{l}1<2,1<3,1<4,1<5,1<6,1<7,2>8,3>4,3>8,4<5, \\
4<6,4>8,5>7,5>8,6>7,6>8,7>8\end{array}$ \\
\hline $\begin{array}{l}\text { a } P<.05 . \\
\text { b } 1=\text { Communal Tables; } 2=\text { Quiet Study; } 3=\text { Computer Lab; } 4=\text { Fishbowls; } 5=\text { Atrium; } 6=\text { Greenspace; } \\
7=\text { Makerspace; 8=Student Union }\end{array}$ \\
\hline
\end{tabular}

of .44, the behaviors explain a greater proportion of the variance in exploring than in exploiting (adjusted $\mathrm{R}^{2}=.13$ ). In part, this is due to the relatively strong explanatory power of questioning behavior (beta $=.46$ ) on exploration.

Also included in the analysis are correlations among the learning and behavior types, along with an additional measure of usage rate. The correlations represent the strength of the relationship among each pair of measures. Similar to beta coefficients, these values may range from +1 to -1 , with +1 indicating a perfect positive relationship, 0 indicating no relationship, and -1 indicating a perfect inverse relationship. The results indicate significant positive associations among learning and behavior, as well as among the behaviors themselves. The results also reveal that student usage is higher in those spaces that support learning and behaviors.

To examine how students from different colleges and years rate spaces, cross-tabulation results were examined for possible relationships. Table 6 reports the frequency counts and percentage distribution of students that report using each space by college and year. This provides an indication of possible location preference based on a student's college or year. The results indicate a significant space utilization relationship for both college $($ chi-square $=82.12 ; \mathrm{df}=35 ; P<.05)$ and year $($ chi-square $=42.27 ; \mathrm{df}$ $=28 ; P<.05)$. Among other relationships, the college results suggest a preference for the Quiet Study space by liberal arts students (44\%), while Makerspace is dominated by engineering students (82\%). For the student year results, the Computer Lab is dominated by third- and fourth-year students, while the Student Union is dominated by first-year students.

\section{Discussion}

Our paper examines the degree to which learning and behavior types are supported in different academic spaces. We discovered that different spaces both within and outside 


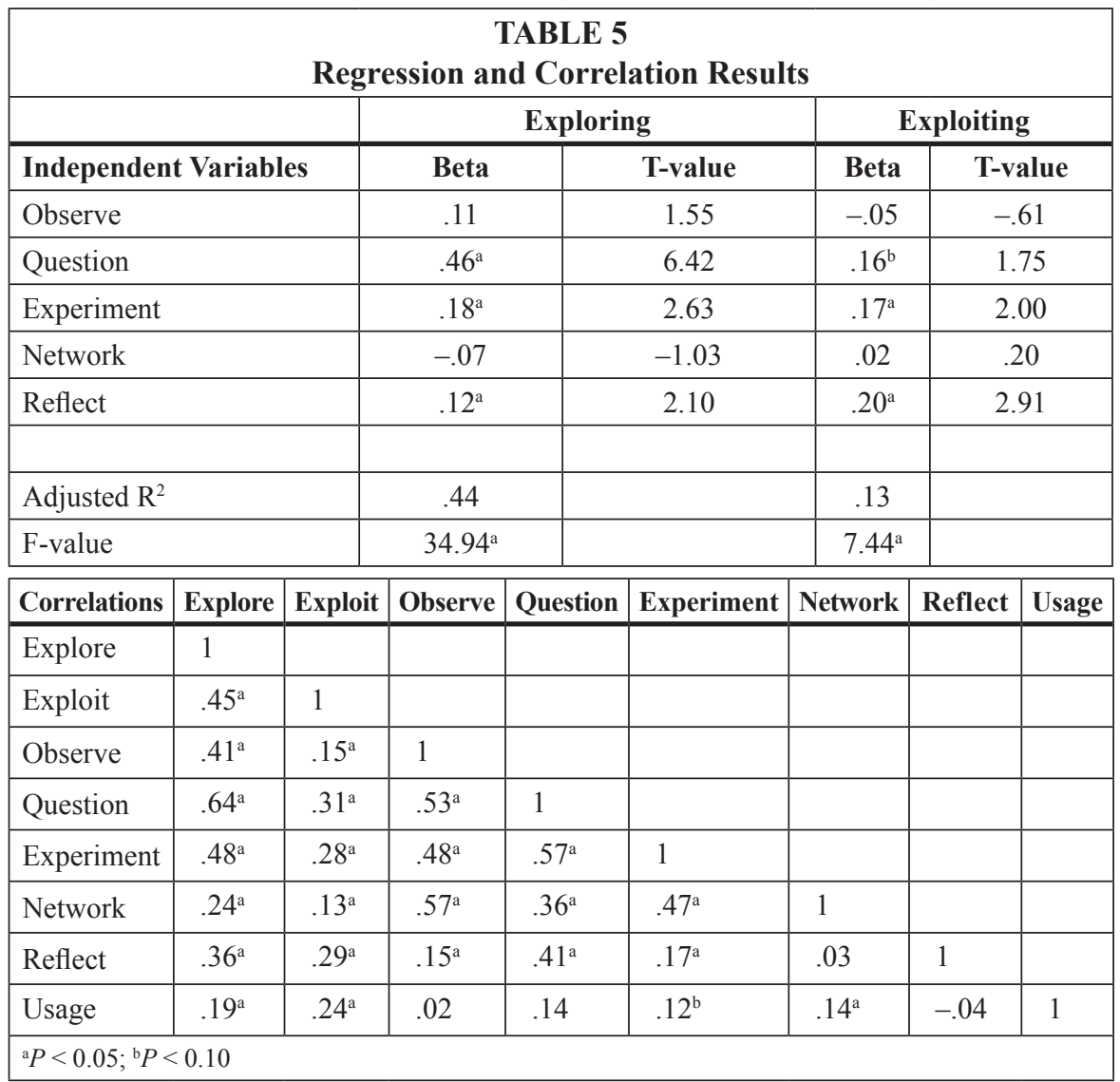

the library support different learning types and behaviors and that certain behaviors are associated with learning types and space usage. While we found the library spaces support exploitive behavior overall, some spaces merge multiple learning types and behaviors while others specialize in one type of learning or behavior. Not surprisingly, the Makerspace encourages nearly all types of innovative behaviors and exploration; however, such spaces do not encourage a crucial aspect of creativity: reflection. The regression findings indicate three key behaviors that support both exploring and exploiting: questioning, reflection, and experimentation. Questioning performs a critical role for exploring; reflection is central to exploitation; and experimenting provides a similar benefit to each. The key is to design spaces that nurture each of these, given that new insights depend on questions, pattern recognition demands reflection, and testing new insights and patterns rely on experimentation. Table 7 lists the spaces we surveyed, a short description, and the learning and behaviors fostered within the space. Note: Nonshaded cells are within the library, while shaded are outside the library.

\section{Exploiting and Exploring}

Most library spaces studied rank higher in exploiting existing ideas over exploring new ideas, so learning adheres to existing paths rather than moving in entirely new directions. What this points to is a lack of experimenting spaces and a lack of spaces to help students develop new creative and innovative ideas. Quiet Study and the Computer Lab rank the highest in spaces where students are likely to exploit existing ideas. 


\begin{tabular}{|c|c|c|c|c|c|c|c|c|c|c|}
\hline \multicolumn{11}{|c|}{$\begin{array}{c}\text { TABLE } 6 \\
\text { Cross-Tab Results for College and Year }\end{array}$} \\
\hline College & & $\begin{array}{c}\text { Communal } \\
\text { Tables }\end{array}$ & $\begin{array}{l}\text { Quiet } \\
\text { Study }\end{array}$ & $\begin{array}{c}\text { Computer } \\
\text { Lab }\end{array}$ & Fishbowls & Atrium & Greenspace & Makerspace & $\begin{array}{c}\text { University } \\
\text { Union }\end{array}$ & Total \\
\hline \multirow[t]{3}{*}{ Architecture } & Count & 0 & 0 & 0 & 4 & 1 & 1 & 0 & 0 & 6 \\
\hline & Location & $0 \%$ & $0 \%$ & $0 \%$ & $15 \%$ & $3 \%$ & $3 \%$ & $0 \%$ & $0 \%$ & $3 \%$ \\
\hline & Total & $0 \%$ & $0 \%$ & $0 \%$ & $2 \%$ & $0 \%$ & $0 \%$ & $0 \%$ & $0 \%$ & $3 \%$ \\
\hline \multirow[t]{3}{*}{ Agriculture } & Count & 1 & 3 & 2 & 5 & 3 & 3 & 1 & 4 & 22 \\
\hline & Location & $4 \%$ & $12 \%$ & $8 \%$ & $19 \%$ & $10 \%$ & $10 \%$ & $4 \%$ & $13 \%$ & $10 \%$ \\
\hline & Total & $0 \%$ & $1 \%$ & $1 \%$ & $2 \%$ & $1 \%$ & $1 \%$ & $0 \%$ & $2 \%$ & $10 \%$ \\
\hline \multirow[t]{3}{*}{ Engineering } & Count & 12 & 4 & 9 & 7 & 10 & 9 & 23 & 8 & 82 \\
\hline & Location & $50 \%$ & $16 \%$ & $36 \%$ & $26 \%$ & $33 \%$ & $29 \%$ & $82 \%$ & $25 \%$ & $37 \%$ \\
\hline & Total & $5 \%$ & $2 \%$ & $4 \%$ & $3 \%$ & $5 \%$ & $4 \%$ & $10 \%$ & $4 \%$ & $37 \%$ \\
\hline \multirow[t]{3}{*}{ Liberal Arts } & Count & 5 & 11 & 3 & 3 & 5 & 7 & 1 & 11 & 46 \\
\hline & Location & $21 \%$ & $44 \%$ & $12 \%$ & $11 \%$ & $17 \%$ & $23 \%$ & $4 \%$ & $34 \%$ & $21 \%$ \\
\hline & Total & $2 \%$ & $5 \%$ & $1 \%$ & $1 \%$ & $2 \%$ & $3 \%$ & $0 \%$ & $5 \%$ & $21 \%$ \\
\hline \multirow{3}{*}{$\begin{array}{l}\text { Science and } \\
\text { Math }\end{array}$} & Count & 6 & 3 & 4 & 0 & 3 & 6 & 1 & 4 & 27 \\
\hline & Location & $25 \%$ & $12 \%$ & $16 \%$ & $0 \%$ & $10 \%$ & $19 \%$ & $4 \%$ & $13 \%$ & $12 \%$ \\
\hline & Total & $3 \%$ & $1 \%$ & $2 \%$ & $0 \%$ & $1 \%$ & $3 \%$ & $0 \%$ & $2 \%$ & $12 \%$ \\
\hline \multirow[t]{3}{*}{ Business } & Count & 0 & 4 & 7 & 8 & 8 & 5 & 2 & 5 & 39 \\
\hline & Location & $0 \%$ & $16 \%$ & $28 \%$ & $30 \%$ & $27 \%$ & $16 \%$ & $7 \%$ & $16 \%$ & $18 \%$ \\
\hline & Total & $0 \%$ & $2 \%$ & $3 \%$ & $4 \%$ & $4 \%$ & $2 \%$ & $1 \%$ & $2 \%$ & $18 \%$ \\
\hline \multirow[t]{3}{*}{ Total } & Count & 24 & 25 & 25 & 27 & 30 & 31 & 28 & 32 & 222 \\
\hline & Location & $100 \%$ & $100 \%$ & $100 \%$ & $100 \%$ & $100 \%$ & $100 \%$ & $100 \%$ & $100 \%$ & $100 \%$ \\
\hline & Total & $11 \%$ & $11 \%$ & $11 \%$ & $12 \%$ & $14 \%$ & $14 \%$ & $13 \%$ & $14 \%$ & $100 \%$ \\
\hline
\end{tabular}




\begin{tabular}{|c|c|c|c|c|c|c|c|c|c|c|}
\hline \multicolumn{11}{|c|}{$\begin{array}{c}\text { TABLE } 6 \\
\text { Cross-Tab Results for College and Year }\end{array}$} \\
\hline Year & & $\begin{array}{c}\text { Communal } \\
\text { Tables }\end{array}$ & $\begin{array}{l}\text { Quiet } \\
\text { Study }\end{array}$ & $\begin{array}{c}\text { Computer } \\
\text { Lab }\end{array}$ & Fishbowls & Atrium & Dexter Lawn & $\begin{array}{c}\text { Innovation } \\
\text { Sandbox }\end{array}$ & $\begin{array}{c}\text { University } \\
\text { Union }\end{array}$ & Total \\
\hline \multirow[t]{3}{*}{ One } & Count & 3 & 4 & 1 & 4 & 3 & 5 & 6 & 15 & 41 \\
\hline & Location & $13 \%$ & $16 \%$ & $4 \%$ & $15 \%$ & $10 \%$ & $16 \%$ & $21 \%$ & $47 \%$ & $19 \%$ \\
\hline & Total & $1 \%$ & $2 \%$ & $0 \%$ & $2 \%$ & $1 \%$ & $2 \%$ & $3 \%$ & $7 \%$ & $19 \%$ \\
\hline \multirow[t]{3}{*}{ Two } & Count & 9 & 11 & 4 & 11 & 6 & 7 & 8 & 7 & 63 \\
\hline & Location & $38 \%$ & $44 \%$ & $16 \%$ & $41 \%$ & $21 \%$ & $23 \%$ & $29 \%$ & $22 \%$ & $29 \%$ \\
\hline & Total & $4 \%$ & $5 \%$ & $2 \%$ & $5 \%$ & $3 \%$ & $3 \%$ & $4 \%$ & $3 \%$ & $29 \%$ \\
\hline \multirow[t]{3}{*}{ Three } & Count & 4 & 5 & 7 & 4 & 9 & 11 & 5 & 4 & 49 \\
\hline & Location & $17 \%$ & $20 \%$ & $28 \%$ & $15 \%$ & $31 \%$ & $35 \%$ & $18 \%$ & $13 \%$ & $22 \%$ \\
\hline & Total & $2 \%$ & $2 \%$ & $3 \%$ & $2 \%$ & $4 \%$ & $5 \%$ & $2 \%$ & $2 \%$ & $22 \%$ \\
\hline \multirow[t]{3}{*}{ Four } & Count & 6 & 4 & 11 & 6 & 9 & 8 & 8 & 4 & 56 \\
\hline & Location & $25 \%$ & $16 \%$ & $44 \%$ & $22 \%$ & $31 \%$ & $26 \%$ & $29 \%$ & $13 \%$ & $25 \%$ \\
\hline & Total & $3 \%$ & $2 \%$ & $5 \%$ & $3 \%$ & $4 \%$ & $4 \%$ & $4 \%$ & $2 \%$ & $25 \%$ \\
\hline \multirow[t]{3}{*}{ Five or more } & Count & 2 & 1 & 2 & 2 & 2 & 0 & 1 & 2 & 12 \\
\hline & Location & $8 \%$ & $4 \%$ & $8 \%$ & $7 \%$ & $7 \%$ & $0 \%$ & $4 \%$ & $6 \%$ & $5 \%$ \\
\hline & Total & $1 \%$ & $0 \%$ & $1 \%$ & $1 \%$ & $1 \%$ & $0 \%$ & $0 \%$ & $1 \%$ & $5 \%$ \\
\hline \multirow[t]{3}{*}{ Total } & Count & 24 & 25 & 25 & 27 & 29 & 31 & 28 & 32 & 221 \\
\hline & Location & $100 \%$ & $100 \%$ & $100 \%$ & $100 \%$ & $100 \%$ & $100 \%$ & $100 \%$ & $100 \%$ & $100 \%$ \\
\hline & Total & $11 \%$ & $11 \%$ & $11 \%$ & $12 \%$ & $13 \%$ & $14 \%$ & $13 \%$ & $14 \%$ & $100 \%$ \\
\hline
\end{tabular}




\begin{tabular}{|c|c|c|c|}
\hline \multicolumn{4}{|c|}{$\begin{array}{l}\text { TABLE } 7 \\
\text { Description of Spaces and Supported Learning and Behaviors }\end{array}$} \\
\hline Space & Description & Learning Supported & Behaviors Supported \\
\hline $\begin{array}{l}\text { Communal } \\
\text { Tables }\end{array}$ & Large group tables & & Networking \\
\hline Quiet Study & Solo tables & Exploiting & Reflection \\
\hline Computer Lab & Solo workstations & Exploiting & Reflecting \\
\hline Fishbowls & $\begin{array}{l}\text { Glass boxes with } \\
\text { communal tables, } \\
\text { group display } \\
\text { (monitor, writing) }\end{array}$ & $\begin{array}{l}\text { Flexible (exploring/ } \\
\text { exploiting) }\end{array}$ & $\begin{array}{l}\text { Observing, Questioning, } \\
\text { Experimenting, and } \\
\text { Reflecting }\end{array}$ \\
\hline Atrium & $\begin{array}{l}\text { Trees, shrubs, } \\
\text { tables, sofas }\end{array}$ & & Question and Reflecting \\
\hline Greenspace & Large lawn & & $\begin{array}{l}\text { Observing, Questioning, } \\
\text { Networking, and } \\
\text { Reflecting }\end{array}$ \\
\hline Makerspace & Makerspace & $\begin{array}{l}\text { Flexible (exploring/ } \\
\text { exploiting) }\end{array}$ & $\begin{array}{l}\text { Observing, Questioning, } \\
\text { Experimenting, and } \\
\text { Reflecting }\end{array}$ \\
\hline Student Union & $\begin{array}{l}\text { Noisy group } \\
\text { seating }\end{array}$ & & $\begin{array}{l}\text { Observing and } \\
\text { Networking }\end{array}$ \\
\hline
\end{tabular}

The Fishbowls rate high in both exploring and exploiting ideas, while the Communal Tables and the Atrium both rate low on exploiting.

\section{Reflect, Question, and Experiment}

Spaces that foster these three behaviors are diverse environments within and outside the library. Reflection is highly ranked in the Computer Lab, Atrium, and Greenspace, while questioning ranks high in the Atrium, but experimenting only ranks high in the Makerspace. We do understand that natural spaces like the Atrium and Greenspace are difficult to place within an existing library; however, there are ways to bring nature into a space, which we recommend. We also see the need for spaces for experimenting within the library, as the library rated low in this type of space.

\section{Flexible Space}

Flexible spaces support both exploring and exploiting. The two spaces that did both was the Makerspace and, to a lesser extent, the Fishbowls. The Makerspace, a designated space for creativity and innovation, also ranked the highest overall in fostering creativity and innovation and the highest in observing, questioning, experimenting, and networking. Given its cramped space filled with hardware, tools, and 3D printers, it is not surprising that it did not rank high in reflection. Within the library, the Fishbowls rated highest overall for fostering creative and innovative thinking, but (compared to the Makerspace) the Fishbowls were weaker in all other behaviors.

The Makerspace is primarily used by engineering students, as it is located within an engineering building. It is recommended that the library create spaces like the Makerspace, which ranks high in exploration, along with most of the other indicators of creativity and innovation. What is ideal about incorporating such a space within a library is that it allows students to move from spaces that allow them to explore, 
experiment, network, and observe to spaces like the Atrium and the Computer Lab for reflection and questioning. This ecosystem of spaces that foster creativity and innovation can very well be housed within one building.

\section{Networking and Questioning Space}

Communal Tables rate high and encourage networking and questioning, but with the noise, movement distractions, and group work going on nearby, the location rates low in reflecting and experimenting. We assumed the Fishbowls and the Communal Tables would rank similarly in all categories, as both are set up for a combination of individual and group work. However, the Fishbowls are walled-in spaces designed for collaboration, whereas the Communal Tables are in a large open space, which is possibly why the Fishbowls rank higher in reflection.

\section{Networking and Observing}

The Student Union (UU) spaces are a mixture of high-top tables for one to four people along with soft seating for individuals or groups. Some seating has window views of campus buildings. The UU differs from library spaces studied, as it is highly trafficked and has numerous visual distractions. Also, there are many ways to move through the space. The layout and human traffic might explain this space as ranking high on both networking and observing.

\section{Reflection Space}

The two outdoor spaces, the Atrium in the library and the Greenspace, both scored high on reflection, possibly because of the relative quiet of the space, an overall lack of technology, and the ability to sit on the lawn or under a tree. The Greenspace differs from the Atrium in that it is located in a highly trafficked area in the campus core, with sidewalks on the perimeter and bisecting the center; hence, this offers a possible reason for it ranking higher than the Atrium for both networking and observing.

\section{Exploitation Space}

The two distinctly solitary spaces studied, Quiet Study and the Computer Lab, are both set up with individual desks or workstations. These two spaces show some interesting similarities and differences. Both spaces (not surprisingly, given their physical setup to either look at a screen or out a window) rate low on observation and networking. What surprised us is that the Computer Lab rates high as a space to exploit ideas, perhaps because of the fully loaded computers at every workstation, which allow for interacting with different types of information.

\section{Further Research and Limitations}

Since this is an exploratory study that studied just one academic library and three campus spaces, further research should be done on other academic library and campus spaces. Additional research on how changes in academic library spaces impact student creativity and innovation is needed. Researchers could test how library spaces impact student creativity and innovation via different methods. Ours only measures types of learning and behaviors associated with library and campus spaces and did not measure the development of creative insights or innovative opportunities. Future research should also consider different phases of creativity and innovation and the types of learning and behaviors associated with each, as well as the type of space that would best support each phase.

While it is helpful to look to the business world for ideas about space design to foster creativity and innovation, we must state that there are crucial differences between the 
ownership of space in academic libraries and businesses. Academic libraries have very few spaces that can be reserved for students, while businesses have offices or cubicles assigned to specific employees. Most academic library spaces are "first come, first served." Businesses also have a limited number of employees who use their spaces, whereas academic libraries have no such limit other than the total enrollment of students. These distinctions are important to note when considering creating spaces like collaboration rooms, innovation labs, or creativity studios that have a controlled set of potential users.

\section{Conclusion}

In conclusion, we recommend that academic libraries be mindful of the need for students to have spaces for quiet contemplation and reflection, collaboration and noisy interaction. These are places to observe, question, experiment, and network. To provide high value for students, it is important that academic libraries use their spaces to foster the highest level of Bloom's taxonomy, that of creativity and innovation. It is important for students to have spaces to reflect, question, and experiment, as our study shows the importance of these three behaviors in supporting exploring and exploiting behaviors. It's critical that library design consider these in support of innovation and creativity. We recommend that academic libraries first understand their different spaces used by students within their library by conducting a space audit for their entire library environment to determine how students use specific spaces. Following such an audit, we recommend that libraries selectively add new types of spaces to encourage behaviors that may not normally happen in an academic library, such as experimenting spaces like makerspaces, which are important for the creative process. Within this process of adding new spaces, we stress that quiet spaces for reflection must be retained; they are important to the creative and innovative process as well. We like the idea of the Noel Studio at Eastern Kentucky University, a dedicated location with trained facilitators available; however, we see such a space as a single element of a complex ecosystem. We believe that creating a set of spaces that foster creativity and innovation is important for the continued success of academic libraries.

\section{Notes}

1. Lorin W. Anderson, David R. Krathwohl, and Benjamin S. Bloom, A Taxonomy for Learning, Teaching, and Assessing: A Revision of Bloom's Taxonomy of Educational Objectives (Boston: Allyn \& Bacon, 2001), 31.

2. Margaret A. Boden, "Creativity in a Nutshell," in The Creative Mind: Myths and Mechanisms (New York: Routledge, 2004), 1.

3. Fariborz Damanpour, "Organizational Complexity and Innovation: Developing and Testing Multiple Contingency Models," Management Science 42, no. 5 (1996): 693--716.

4. James G. March, "Exploration and Exploitation in Organizational Learning," Organization Science 2, no. 1 (1991): 71-87.

5. Jeffrey H. Dyer, Hal B. Gregersen, and Clayton Christensen, "Entrepreneur Behaviors, Opportunity Recognition, and the Origins of Innovative Ventures," Strategic Entrepreneurship Journal 2, no. 4 (2008): 317-38.

6. Anil K. Gupta, Ken G. Smith, and Christina E. Shalley, "The Interplay between Exploration and Exploitation," Academy of Management Journal 49, no. 4 (2006): 693-706.

7. Michele Rigolizzo and Teresa Amabile, "Entrepreneurial Creativity: The Role of Learning Processes and Work Environment Supports" in The Oxford Handbook of Creativity, Innovation, and Entrepreneurship, eds. C.E. Shalley, M.A. Hitt, and J. Zhou (Oxford: Oxford University Press, 2015), 61-78.

8. Steven J. Tepper, “The Creative Campus: Who's No. 1?" Chronicle of Higher Education 51, no. 6 (2004): B6-B8.

9. David Carr, A Place Not a Place: Reflection and Possibility in Museums and Libraries (New York: Almira Press, 2006): 7-8.

10. Ibid, 6. 
11. See, for example: Michael J. Khoo, Lily Rozaklis, Catherine Hall, and Diana Kusunoki, "'A Really Nice Spot': Evaluating Place, Space, and Technology in Academic Libraries," College and Research Libraries 77, no. 1 (2016): 51-70; Rachel Applegate, "The Library Is for Studying: Student Preferences for Study Space," Journal of Academic Librarianship 35, no. 4 (July 2009): 341-46; Heather V. Cunningham and Susanne Tabur, "Learning Space Attributes: Reflections on Academic Library Design and Its Use," Journal of Learning Spaces 1, no. 2 (2012), available online at http://libjournal. uncg.edu/ojs/index.php/jls/article/view/392 [accessed 24 September 2015]; Charles Crook and Gemma Mitchell, "Ambience in Social Learning: Student Engagement with New Designs for Learning Spaces," Cambridge Journal of Education 42, no. 2 (2012): 121-39.

12. Lisa Kurt, William Kurt, and Ann Medaille, "The Power of Play: Fostering Creativity and Innovation in Libraries," Journal of Library Innovation 1, no. 1 (2010): 8-23.

13. John Burke, "Making Sense: Can Makerspaces Work in Academic Libraries?" paper presented at ACRL Annual Conference, Portland, Oregon, March 25-28, 2015, available online at www.ala.org/acrl/sites/ala.org.acrl/files/content/conferences/confsandpreconfs/2015/Burke.pdf [accessed 27 April 2015].

14. Valerie Zeithaml, "Physical Evidence and the Servicescape," in Services Marketing, eds. Valerie A. Zeithaml, Mary Jo Bitner, and Dwayne D. Gremler (Boston: McGraw-Hill/Irwin, 2006), 331.

15. Marilyn J. Bitner, "Servicescapes: The Impact of Physical Surroundings on Customers and Employees," Journal of Marketing 56 (1992): 60.

16. Lennie Scott-Weber, In Sync: Environmental Behavior Research and the Design of Learning Spaces (Ann Arbor, Mich.: Society for College and University Planning, 2004), 58-62.

17. Janetta M. McCoy and Gary W. Evans, "The Potential Role of the Physical Environment in Fostering Creativity," Creativity Research Journal 14, no. 3/4 (2002): 409-26.

18. Markus F. Peschl and Thomas Fundneider,"Spaces Enabling Game-Changing and Sustaining Innovations: Why Space Matters for Knowledge Creation and Innovation," Journal of Organisational Transformation \& Social Change 9, no. 1 (2012): 41-61.

19. See, for example: Tore Kristensen, "The Physical Context of Creativity," Creativity and Innovation Management 13, no. 2 (2004): 89-96; Kerstin Sailer, "Creativity as Social and Spatial Process," Facilities 29, no. 1/2 (2011): 6-18.

20. "Navigation Center® Systems," MG Taylor Corporation, available online at www.mgtaylor. com/public/2001/nav_centers.html [accessed 1 August 2015].

21. "What Is a Navigation Center ${ }^{\mathrm{TM}}$ ?" MG Taylor Corporation, available online at www.mgtaylor. com/public/2002/pdf/white_nav_final.PDF [accessed 1 August 2015].

22. Joyce Wycoff and Lynn Snead, "Stimulating Innovation with Collaboration Rooms," Journal for Quality and Participation 22, no. 2 (1999): 55.

23. Udo-Ernst Haner, "Spaces for Creativity and Innovation in Two Established Organizations," Creativity and Innovation Management 14, no. 3 (2005): 288-98.

24. Ibid.

25. Michael Lewis and James Moultrie, "The Organizational Innovation Laboratory," Creativity and Innovation Management 14, no. 1 (2005): 73-83.

26. Ibid., 73.

27. Wissam Magadley and Kamal Birdi, "Innovation Labs: An Examination into the Use of Physical Spaces to Enhance Organizational Creativity," Creativity and Innovation Management 18, no. 4 (2009): 315-25.

28. Jeffrey T. Gayton, “Academic Libraries: 'Social' or 'Communal?' The Nature and Future of Academic Libraries," Journal of Academic Librarianship 34, no. 1 (2008): 60-66.

29. Scott Bennett, "Putting Learning into Library Planning," portal: Libraries and the Academy 15, no. 2 (2015): 215-31.

30. Hannah Bennett, "Buildings with Brain Power: Library Architecture in Neural Terms," paper presented at IFLA WLIC 2014, Lyon: Libraries, Citizens, Societies: Confluence for Knowledge in Session 149-Art Libraries with Science and Technology Libraries, Lyon, France, August 16-22 2014.

31. Megan Lotts, "Implementing a Culture of Creativity: Pop-up Making Spaces and Participating Events in Academic Libraries," College \& Research Libraries News 76, no. 2 (2015): 72-75.

32. Megan Lotts, "Lego® Play: Implementing a Culture of Creativity and Making in the Academic Library," paper presented at ACRL Annual Conference, Portland OR, March 25-28, 2015, available online at www.ala.org/acrl/sites/ala.org.acrl/files/content/conferences/confsandpreconfs/2015/Lotts.pdf_[accessed 16 April 2015].

33. Jennifer Sparrow and Susan Whitmer, "Transforming the Student Experience through Learning Space Design," in The Future of Learning and Teaching in Next Generation Learning Spaces (International Perspectives on Higher Education Research, Volume 12) (Bingley: Emerald Group Publishing Limited 12, 2014), 299-315. 
34. Elizabeth Long Lingo and Steven J. Tepper, "The Creative Campus: Time for a 'C' Change," Chronicle of Higher Education 57, no. 8 (2010).

35. "About the Space," Eastern Kentucky University Noel Studio for Academic Creativity, available online at http://studio.eku.edu/about-space [accessed 15 July 2015].

36. Betina Gardner, Trenia L. Napier, and Russell Carpenter, "Reinventing Library Spaces and Services: Harnessing Campus Partnerships to Initiate and Sustain Transformational Change," Advances in Librarianship 37 (2013): 135-51.

37. Joseph F. Hair, William Black, Barry J. Babin, and Rolph E. Anderson, Multivariate Data Analysis, 7/e (Upper Saddle River, N.J.: Prentice Hall, 2009).

38. William G. Zikmund, Barry J. Babin, Jon C. Carr, and Mitch Griffin, Business Research Methods, 9th ed. (Mason, Ohio: South-Western, 2013), 327-18.

39. Hair et al., Multivariate Data Analysis, 125.

40. Zikmund et al., Business Research Methods, 302.

41. Ibid., 539.

42. Ibid., 542. 